\title{
Ionic transport in P(VdF-HFP)-PEO based novel microporous polymer electrolytes
}

\author{
M DEKA and A KUMAR* \\ Department of Physics, Tezpur University, Napaam, Tezpur 784 028, India
}

MS received 1 November 2008; revised 9 March 2009

\begin{abstract}
A novel microporous polymer electrolyte (MPE) comprising blends of poly(vinylidene fluoride-cohexafluoropropylene) [P(VdF-HFP)] and polyethylene oxide (PEO) was prepared by phase inversion technique. It was observed that addition of $P E O$ improved the pore configuration, such as pore size, pore connectivity and porosity of $\mathrm{P}(\mathrm{VdF}-\mathrm{HFP})$ based membranes. The room temperature ionic conductivity was significantly enhanced. The highest porosity of about $65 \%$ and ionic conductivity of about $7 \times 10^{-4} \mathrm{~S} \mathrm{~cm}^{-1}$ was obtained when the weight ratio of PEO was $40 \%$. The liquid electrolyte uptake was found to increase with increase in porosity and pore size. However, at higher weight ratio of PEO $(>40 \%)$ porosity, pore size and ionic conductivity was decreased. This descending trend with further increase of PEO weight ratio was attributed to conglomeration effect of PEO at the pores.
\end{abstract}

Keywords. P(VdF-HFP); microporous membrane; phase inversion technique; ionic conductivity; porosity.

\section{Introduction}

Research on rechargeable lithium batteries has gained an unprecedented significance in the rapid development of new consumer electronic technologies such as cell phones, notebook PC and electric vehicles (Scrosati et al 2001; Tarascon and Armand 2001; Arico et al 2005). Compared with liquid electrolytes, polymer electrolytes offer flexibility and shape versatility which provides them a compelling rationale to use in rechargeable lithium batteries. The development of polymer electrolytes has passed mainly three stages (Meyer 1998; Murata et al 2001): solid polymer electrolytes (SPEs) (Zhou and Fedkiw 2004), gel polymer electrolytes (GPEs) (Song et al 1999) and microporous polymer electrolytes (MPEs) (Boudin et al 1999). From industrial point of view MPEs have received considerable attention due to their high ionic conductivity and excellent mechanical properties (Choi et al 2003; Cheng et al 2004).

Microporous polymer electrolyte membranes can be prepared by conventional phase inversion technique (Wienk et al 1996; Pasquier et al 2000; Zhang et al 2004). However, in this process, due to the use of large amounts of expensive, harmful and flammable solvents, contamination of the porous membrane may take place by the residual solvents. Moreover, preparation of MPEs by conventional phase inversion technology is costly and time consuming. Evaporation phase inversion was then proposed where the polymer solutions in volatile solvent

$\overline{\text { *Author for correspondence (ask@tezu.ernet.in) }}$ acetone are prepared with non-solvents of butanol, methanol, pentane, ethanol, hexane or their binary mixture and the porous membranes are obtained after cast and evaporation of volatile components ( $\mathrm{Pu}$ et al 2006). This process is more effective and cost saving.

In this work, a MPE based on blends of poly (vinylidene fluoride-co-hexafluoropropylene) $\{\mathrm{P}(\mathrm{VdF}-$ HFP) $\}$ and polyethylene oxide (PEO) was prepared by phase inversion technique taking acetone as solvent and ethanol as non-solvent because they are miscible and have different boiling points. It was observed that when PEO concentration was varied, good microporous structure of the membranes were obtained at $40 \mathrm{wt} . \%$ of PEO leading to maximum ionic conductivity.

\section{Experimental}

P(VdF-HFP) $\left(\mathrm{M}_{\mathrm{w}}=400,000\right)$, PEO $\left(\mathrm{M}_{\mathrm{w}}=600,000\right)$ and the salt $\left(\mathrm{LiClO}_{4}\right)$ were received from Aldrich, USA. Both the polymers were heated at $323 \mathrm{~K}$ and $\mathrm{LiClO}_{4}$ was heated at $373 \mathrm{~K}$ to remove the moisture. Samples were prepared by dissolving $\mathrm{P}(\mathrm{VdF}-\mathrm{HFP})$ and $\mathrm{PEO}$ in a mixture of acetone (solvent) and ethanol (non-solvent) $(\mathrm{v} / \mathrm{v}=8 / 2)$. After stirring for $4-5 \mathrm{~h}$ at $313 \mathrm{~K}$, the resulting homogeneous mixture was cast onto ultrasonically cleaned glass plate and allowed to dry at $353 \mathrm{~K}$ for 5-6 h. In the drying process, solvent (acetone) and non-solvent (ethanol) evaporated and the empty locations of ethanol formed micro-pores. Finally opaque freestanding membranes were obtained. The concentration of PEO was varied from 10 to $60 \mathrm{wt} . \%$ and the membranes used in the 
study were denoted as $\mathrm{P}(\mathrm{VdF}-\mathrm{HFP})-x \%$ PEO (where $x=10,20,30,40,50,60$ ).

The liquid electrolyte used in this study was $1 \mathrm{~mol}$ $\mathrm{LiClO}_{4}$ in $1: 1(\mathrm{v} / \mathrm{v})$ mixture of propylene carbonate (PC) and diethyl carbonate (DEC). Weight uptake of $\mathrm{P}(\mathrm{VdF}-$ HFP) $-x \%$ PEO blend microporous membranes were measured as a function of soaking time in liquid electrolyte to activate porous polymer membranes for $6 \mathrm{~h}$ and calculated as follows (Vijayakumar et al 2008):

$$
\text { Weight uptake }(\%)=\left(W_{\mathrm{t}}-W_{0}\right) / W_{0} \times 100,
$$

where $W_{\mathrm{t}}$ and $W_{0}$ are the weight of the wet and dry polymer membranes, respectively.

Porosity of $\mathrm{P}(\mathrm{VdF}-\mathrm{HFP})-x \%$ PEO membranes was measured by immersing the membrane into 1-butanol for $2 \mathrm{~h}$ and calculated using the following equation (Xi et al 2006a):

$$
\text { Porosity }(\%)=\left(W_{\mathrm{t}}-W_{0}\right) / \rho V \times 100 \text {, }
$$

where $W_{\mathrm{t}}$ and $W_{0}$ are the weight of the wet and dry polymer membranes, respectively, $V$ the apparent volume of the membrane and $P$ the density of 1-butanol.

The surface morphology of $\mathrm{P}(\mathrm{VdF}-\mathrm{HFP})-x \%$ PEO blend microporous membranes were studied by scanning electron microscopy (SEM) using Jeol model JSM $6390 \mathrm{LV}$. The ionic conductivity of the microporous polymer electrolytes were determined from the complex impedance plots obtained by using a Hioki 3532-50 LCR $\mathrm{Hi}$ Tester in the frequency range $42 \mathrm{~Hz}$ to $5 \mathrm{MHz}$. X-ray diffractograms were studied by Rigaku miniflex diffractometer to calculate the degree of crystallinity of the prepared microporous membranes. FTIR studies have been conducted to investigate the structural and complexation in the microporous polymer electrolytes.

\section{Results and discussion}

\subsection{Morphology, porosity and electrolyte uptake of the microporous membranes}

The microporous membranes prepared in this work were composed of two materials: mechanically strong $\mathrm{P}(\mathrm{VdF}-$ HFP) (Wu et al 2006) and flexible PEO. Figure 1 shows the surface morphology of $\mathrm{P}(\mathrm{VdF}-\mathrm{HFP})-x \% \mathrm{PEO}$ porous membranes. It is observed that pore size of the membranes increases with increase in PEO concentration up to $40 \mathrm{wt} \%$ (figures $1 \mathrm{a}-\mathrm{d}$ ) and then decreases with further increase in PEO content (figures $1 \mathrm{e}-\mathrm{f}$ ). The increase in pore size up to $40 \mathrm{wt} . \%$ of PEO content is possibly due to easier evaporation of non-solvent (ethanol) from flexible PEO than from rigid $\mathrm{P}(\mathrm{VdF}-\mathrm{HFP})$ (Jeon and Kwak 2006). Figures $1(e-f)$ reveal the decrease in pore size of as prepared membranes at 50 and $60 \mathrm{wt} \%$ of PEO. Decrease in pore size beyond $40 \mathrm{wt} \%$ of PEO could be attributed to conglomeration of PEO near the pores (Jeon et al 2005). This conglomeration occurs due to the inversion effect of host matrix from a $\mathrm{P}(\mathrm{VdF}-\mathrm{HFP})$ rich phase to a PEO-rich phase, which results in decrease in pore size and porosity at PEO concentration $>40 \mathrm{wt} . \%$.

Figure 2 displays the variation of porosity of $\mathrm{P}(\mathrm{VdF}-$ HFP) $-x \%$ PEO microporous membranes with gradual increase of PEO concentration. It is seen that porosity first increases as a function of PEO concentration and reaches maximum $(65.2 \%)$ when the weight ratio of PEO is $40 \%$ and subsequently decreases at higher weight ratio of PEO. This variation in porosity is consistent with the change of pore configuration as observed in SEM images (figure 1).

The liquid electrolyte uptake plots of $\mathrm{P}(\mathrm{VdF}-\mathrm{HFP})-x \%$ PEO microporous membranes are shown in figure 3 . The figure shows that the liquid electrolyte uptake of $\mathrm{P}(\mathrm{VdF}-$ HFP) $-x \%$ PEO microporous membranes are greatly influenced by PEO concentration and is consistent with the variation of porosity of the membranes. As PEO content increases resulting in greater porosity, the liquid electrolyte uptake also increases, suggesting that $\mathrm{P}(\mathrm{VdF}-$ HFP) $-x \%$ PEO microporous membranes can store more liquid electrolytes when its porosity increases. Beyond $40 \mathrm{wt}$ \% of PEO content both porosity and liquid electrolyte uptake decreases which is attributed to conglomeration of PEO near the pores as mentioned earlier.

\subsection{Ionic conductivity}

Figure 4 shows the room temperature complex impedance spectra of $\mathrm{P}(\mathrm{VdF}-\mathrm{HFP})-x \%$ PEO microporous polymer electrolytes at different concentrations of PEO. The ionic conductivity of $\mathrm{P}(\mathrm{VdF}-\mathrm{HFP})-x \%$ PEO microporous polymer electrolytes is calculated from $\sigma=1 / R_{\mathrm{b}} r^{2} \pi$; where ' $l$ ' and ' $r$ ' are thickness and radius of the sample membrane discs and $R_{\mathrm{b}}$ the bulk resistance obtained from complex impedance plots. It is accepted that $R_{\mathrm{b}}$ could be obtained from the intercept on the real axis at the high frequency end of the Nyquist plot of complex impedance (Watanabe et al 1985; Abraham et al 1997). The variation of room temperature ionic conductivity with different weight ratios of PEO is shown in figure 5. From the plot it is seen that room temperature ionic conductivity of the microporous polymer electrolytes follow the same trend as that of porosity and liquid electrolyte uptake as a function of PEO content. It is worth mentioning that with increase in PEO content the ionic conductivity increases and becomes maximum $\left(6.85 \times 10^{-4} \mathrm{~S} / \mathrm{cm}\right)$ at $40 \mathrm{wt} . \%$ of PEO and decreases at higher PEO content (>40 wt.\%). This result confirms that uptake is dependent on pore size as well as on porosity because liquid electrolyte can more easily penetrate into the membrane with larger pores resulting in higher ionic conductivity (Song et al 2000; Wang et al 2000). The enhancement in ionic conductivity upon addition of PEO up to $40 \mathrm{wt} . \%$ could 

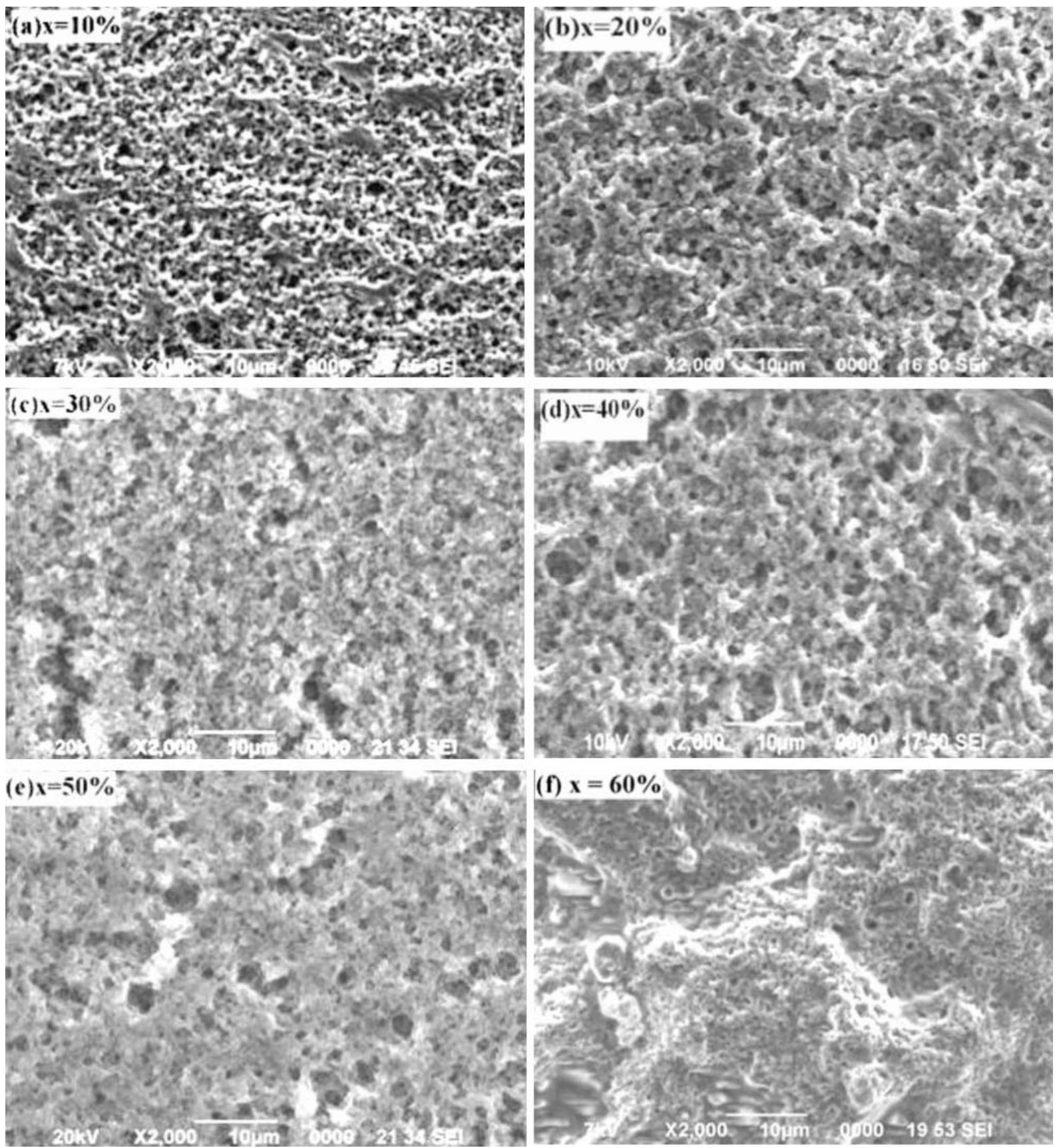

Figure 1. Surface SEM micrographs of $\mathrm{P}(\mathrm{VdF}-\mathrm{HFP})-x \%$ PEO porous membranes: (a) $x=10 ;(\mathbf{b}) x=20 ;(\mathbf{c}) x=30$; (d) $x=40 ;(\mathbf{e}) x=50$ and (f) $x=60$

also be due to improved pore connectivity, which is very important for charge carrier transport in microporous polymer electrolyte (Xi et al 2006).

The decreased ionic conductivity at higher PEO content $(>40 \mathrm{wt} . \%)$ can be explained by the conglomeration effect as mentioned earlier. The conglomeration of PEO near the pores reduces the pore size and porosity, which resists further uptake of liquid electrolyte in $\mathrm{P}(\mathrm{VdF}-$ HFP) $-x \%$ PEO microporous membranes resulting in lower ionic conductivity. Moreover, at higher PEO con- tent the phase separation between PEO and P(VdF-HFP) happens leading to the decrease in ionic conductivity. The phase separation effect is confirmed by XRD results.

Figure 6 shows the conductivity vs temperature inverse plots of $\mathrm{P}(\mathrm{VdF}-\mathrm{HFP})-x \%$ PEO microporous polymer electrolytes. The curvature shown in this plot indicates that the ionic conduction obeys the VTF (Vogel-TammanFulcher) relation (Quartarone et al 1998) given by

$$
\sigma=\sigma_{0} \exp \left(-B / / k\left(T-T_{0}\right)\right),
$$


where $B$ is a constant, whose dimensions are that of energy, $T_{0}$ the temperature at which the probability of configurational transition tends to zero. The above equation describes the transport properties in a viscous matrix. The conductivity enhancement behaviour with temperature can be understood by free volume model (Rajendran and Uma 2000). As the temperature increases, the polymer chains flex and expand at increasing rate and produce free volume leading to an increase in ion and segmental mobility which facilitates ion transport (Saikia and Kumar 2005).

\subsection{X-ray diffraction studies}

X-ray diffraction patterns of pure PEO and P(VdF-HFP) are presented in figures $7(a-b)$. In figure $7 b$ the peaks at

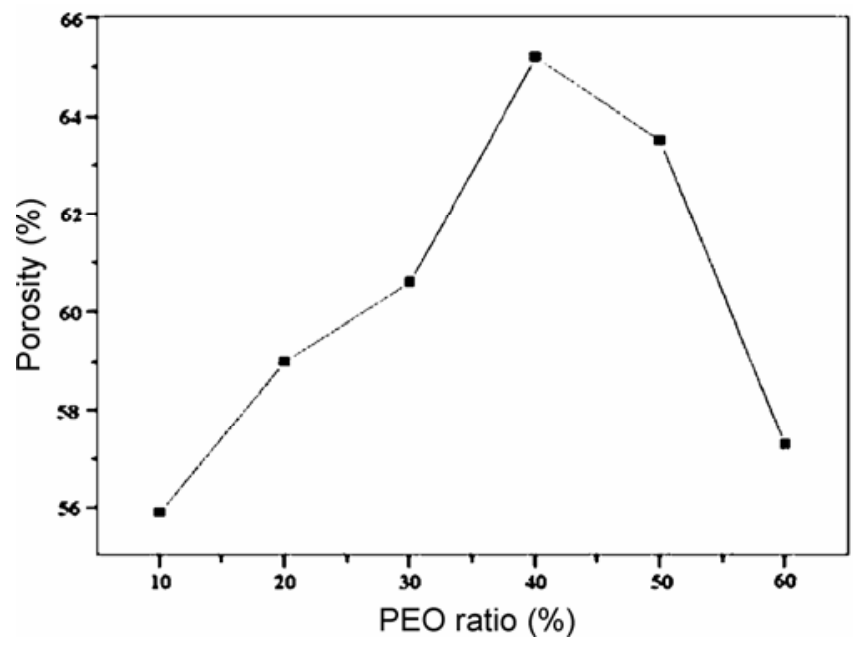

Figure 2. Porosity of $\mathrm{P}(\mathrm{VdF}-\mathrm{HFP})-x \%$ PEO microporous membranes as a function of $\mathrm{PEO}$ weight ratio.

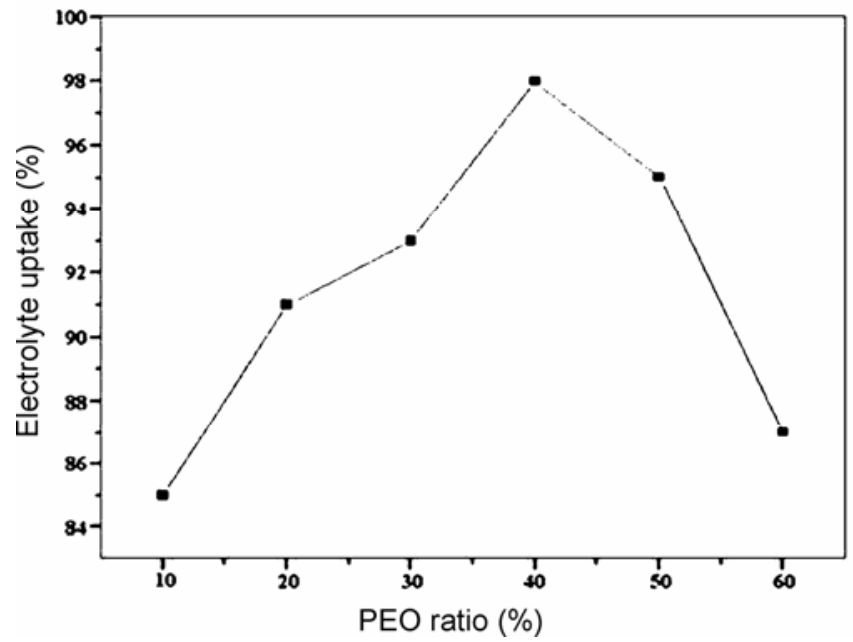

Figure 3. Liquid electrolyte uptake of $\mathrm{P}(\mathrm{VdF}-\mathrm{HFP})-x \%$ PEO microporous membranes as a function of $\mathrm{PEO}$ weight ratio.
$2 \theta=20^{\circ}$ and $38^{\circ}$ correspond to (020) and (202) crystalline peaks of $\mathrm{P}(\mathrm{VdF}-\mathrm{HFP})$. This confirms the partial crystallization of $\mathrm{PVdF}$ units in the copolymer and gives a semi-crystalline structure of $\mathrm{P}(\mathrm{VdF}-\mathrm{HFP})$ (Saikia and Kumar 2004). PEO shows a characteristic peak at $2 \theta=20^{\circ}$ and $23^{\circ}$ (figure $7 \mathrm{a}$ ). Figure 8 shows the XRD spectra of $\mathrm{P}(\mathrm{VdF}-\mathrm{HFP})-x \%$ PEO microporous membranes with different weight ratios of $\mathrm{PEO}$. It is observed that when $\mathrm{P}(\mathrm{VdF}-\mathrm{HFP})$ is blended with $\mathrm{PEO}$, no additional peak appears up to $40 \mathrm{wt} \%$ of PEO; only the intensity of crystalline peaks decreases suggesting that the amorphicity increases (Leo et al 2002). In addition, at 50 and $60 \mathrm{wt} \%$ of PEO concentration additional peak appears at $2 \theta=23^{\circ}$ which can be assigned to characteristic peak of PEO (figures $8(\mathrm{e}, \mathrm{f})$ ), which indicates that above $40 \mathrm{wt} . \%$, PEO gets phase separated from the polymer electrolyte phase. The degree of crystallinity of the microporous membranes were determined by using a method described

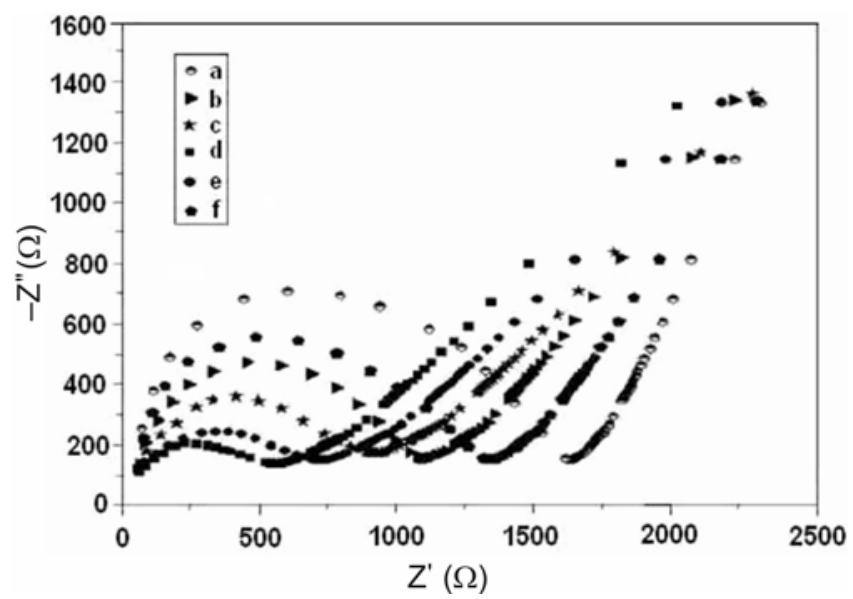

Figure 4. Room temperature impedance plots of $\mathrm{P}(\mathrm{VdF}-$ HFP) $-x \%$ PEO microporous membranes: (a) $x=10$; (b) $x=20$; (c) $x=30$; (d) $x=40$; (e) $x=50$ and (f) $x=60$.

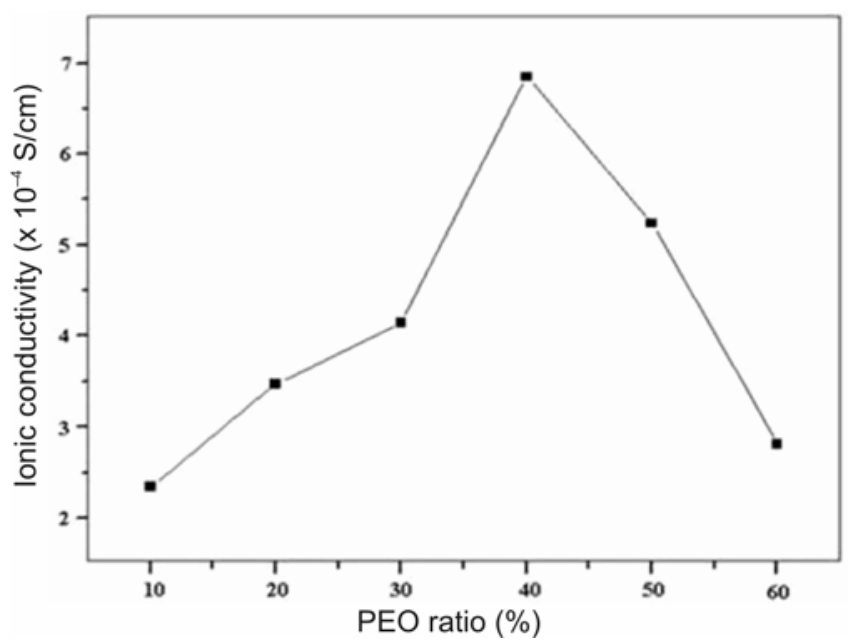

Figure 5. Ionic conductivity of $\mathrm{P}(\mathrm{VdF}-\mathrm{HFP})-x \%$ PEO microporous membranes as a function of $\mathrm{PEO}$ weight ratio. 
elsewhere (Saikia et al 2006). It was observed that degree of crystallinity decreases with increasing PEO content and becomes a minimum $(15 \cdot 2 \%)$ when the weight ratio of PEO is $40 \%$. The broadening of the peaks confirms this result (figure 8). This reduction in crystallinity upon addition of PEO could be attributed to the increase in porosity and liquid electrolyte uptake of the microporous membranes. The ionic conductivity increases with decrease in crystallinity due to the fact that ionic conduction essentially occurs through the amorphous phase in the polymer electrolytes (Panero et al 2002).



Figure 6. Temperature dependence of ionic conductivity of P(VdF-HFP)- $x \%$ PEO microporous polymer electrolytes: (a) $x=10$; (b) $x=20$; (c) $x=30$; (d) $x=40$; (e) $x=50$ and (f) $x=60$.



Figure 7. XRD spectra of (a) $\mathrm{PEO}$ and (b) $\mathrm{P}(\mathrm{VdF}-\mathrm{HFP})$.

\subsection{FTIR analysis}

FTIR is a powerful tool to study the local structural changes. The infrared spectrum is sensitive to both situations where complexations occur in crystalline or amorphous phase. The FTIR spectra as shown in figure 9 are evidence for interactions between the polymer and salt.

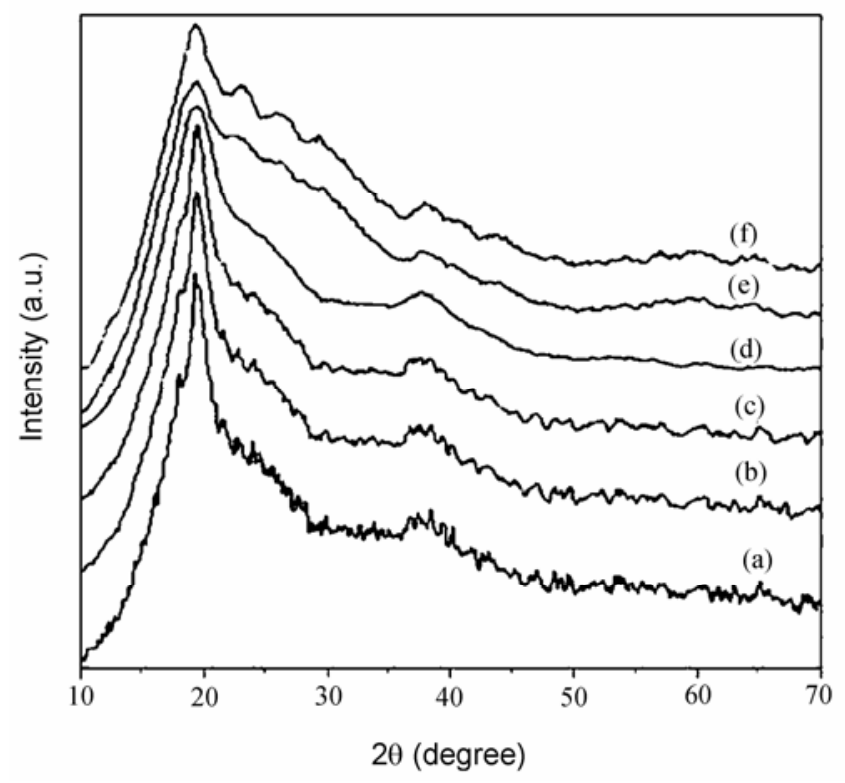

Figure 8. $\mathrm{XRD}$ spectra of $\mathrm{P}(\mathrm{VdF}-\mathrm{HFP})-x \%$ PEO microporous membranes: (a) $x=10$; (b) $x=20$; (c) $x=30$; (d) $x=40$; (e) $x=50$ and (f) $x=60$.



Figure 9. FTIR spectra of (a) $\mathrm{LiClO}_{4}$, (b) pure PEO, (c) pure $\mathrm{P}(\mathrm{VdF}-\mathrm{HFP})$, (d) $\mathrm{P}(\mathrm{VdF}-\mathrm{HFP})-30 \%$ PEO and (e) P(VdFHFP) $-50 \%$ PEO. 
The stretching and bending modes of $\left(\mathrm{CH}_{2}\right)_{\alpha}$ of pure PEO are observed at $1470.25 \mathrm{~cm}^{-1}$ and $1353.91 \mathrm{~cm}^{-1}$, respectively which get shifted to $1455.33 \mathrm{~cm}^{-1}, 1351.36 \mathrm{~cm}^{-1}$ in $30 \mathrm{wt} \%$ of PEO concentration (figure 9d) and $1454.87 \mathrm{~cm}^{-1}, 1351.56 \mathrm{~cm}^{-1}$ in $50 \mathrm{wt} . \%$ of PEO concentration (figure 9e). The peak at $1104.2 \mathrm{~cm}^{-1}$ is assigned to $v(\mathrm{C}-\mathrm{O}-\mathrm{C})$ of PEO molecule (Yang et al 2005) which also gets shifted to $1113.05 \mathrm{~cm}^{-1}$ and $1080 \mathrm{~cm}^{-1}$ for $30 \mathrm{wt} \%$ and $50 \mathrm{wt} \%$ of PEO concentrations in $\mathrm{P}(\mathrm{VdF}-\mathrm{HFP})-x \%$ PEO microporous polymer electrolytes. The frequency, $3000 \mathrm{~cm}^{-1}$, is assigned to $\mathrm{C}-\mathrm{H}$ stretching vibration of $\mathrm{PVdF}$. The frequency $1783 \mathrm{~cm}^{-1}$ is assigned to $-\mathrm{CF}=\mathrm{CF}_{2},-\mathrm{C}-\mathrm{O}-\mathrm{CO}-\mathrm{O}-\mathrm{C}-$ group (Saikia and Kumar 2005). Frequency $882 \mathrm{~cm}^{-1}$ is assigned to vinylidene group of PVdF. All these peaks are shifted in the polymer electrolyte to $3020.62 \mathrm{~cm}^{-1}, 1765 \mathrm{~cm}^{-1}$ and $882.76 \mathrm{~cm}^{-1}$ in $30 \mathrm{wt} . \%$ of PEO and that to $3021.58 \mathrm{~cm}^{-1}, 1777.95 \mathrm{~cm}^{-1}$, $880.08 \mathrm{~cm}^{-1}$ in $50 \mathrm{wt} \% \%$ of PEO. The peak at $626 \mathrm{~cm}^{-1}$ is due to the salt, $\mathrm{LiClO}_{4}$ and because of polymer-salt interaction it gets shifted to $625.67 \mathrm{~cm}^{-1}$ and $626.73 \mathrm{~cm}^{-1}$ in $30 \mathrm{wt} . \%$ and $50 \mathrm{wt} . \%$ of PEO, respectively. The increased or decreased manner of shifting of frequency from pure $\mathrm{PEO}$ and pure $\mathrm{P}(\mathrm{VdF}-\mathrm{HFP})$ shows the interaction of the two polymers and salt in $\mathrm{P}(\mathrm{VdF}-\mathrm{HFP})$ based microporous polymer electrolytes.

\section{Conclusions}

A novel MPE based on P(VdF-HFP)-PEO blend has been prepared by a simple phase inversion method wherein PEO has been added to effectively control the pore size and porosity, which are strongly correlated with their uptake and ionic conductivity of the MPEs. The liquid electrolyte uptake and room temperature ionic conductivity are greatly enhanced upon addition of PEO and become a maximum at 40 wt.\% PEO. SEM micrographs clearly show the increase in pore size with increase in PEO content. The increased pore size results in an increase in ionic conductivity and decrease in degree of crystallinity as confirmed by a.c. impedance analysis and XRD spectra, respectively. Beyond $40 \mathrm{wt} \%$ of PEO, conglomeration takes place which decreases the pore size as observed in SEM results. The conglomeration effect predominates at higher concentration of PEO and as a result ionic conductivity, porosity and liquid electrolyte uptake follow a descending trend. The enhanced ionic conductivity and liquid electrolyte uptake lead MPEs to become good candidates for rechargeable lithium batteries.

\section{Acknowledgements}

The authors would like to thank Mr Ratan Barua, Department of Physics, Tezpur University, Tezpur, for extending help in taking SEM. Authors also sincerely thank Mr A K Nath and Ms B Phukan for their help in carrying out XRD and conductivity measurements.

\section{References}

Abraham K M, Jiang Z and Carroll B 1997 Chem. Mater. 9 1978

Arico A S, Bruce P G, Scrosati B, Tarascon J M and Schalkwijk W V 2005 Nat. Mater. 4366

Boudin F, Andrieu X, Jehoulet C and Olsel I I 1999 J. Power Sources 81-82 804

Cheng C L, Wan C C and Wang Y Y 2004 Electrochem. Commun. 6531

Choi S W, Jo S M, Lee W S and Kim Y R 2003 Adv. Mater. 15 2027

Jeon J D and Kwak S Y 2006 J. Membrane Sci. 28615

Jeon J D, Cho B W and Kwak S Y 2005 J. Power Sources 143 219

Leo C J, Subba Rao G V and Chowwdari B V R 2002 Solid State Ion 148159

Meyer W H 1998 Adv. Mater. 10439

Murata K, Izuchi S and Yoshihisa Y 2000 Electrochim. Acta 45 1501

Panero S, Satolli D, D'Epifano A and Scrosati B 2002 J. Electrochem. Soc. A149 414

Pasquier A D, Warren P C, Culver D, Gozdz A S, Amatucci G G and Tarascon J M 2000 Solid State Ion. 135249

$\mathrm{Pu}$ W, He X, Wang L, Jiang C and Wan C 2006 J. Membrane Sci. 27211

Quartarone E, Nustareli P and Magistris A 1998 Solid State Ion 1101

Rajendran S and Uma T 2000 J. Power Sources 88282

Saikia D and Kumar A 2004 Electrochim. Acta 492581

Saikia D and Kumar A 2005 Eur. Polym. J. 41563

Saikia D, Kumar A, Singh F and Avasthi D K 2006 J. Phys. D: Appl. Phys. 394208

Scrosati B, Croce F and Panero S 2001 J. Power Sources 100 93

Song J Y, Wang Y Y and Wan C C 1999 J. Power Sources 77 183

Song J Y, Wang Y Y and Wan C C 2000 J. Electrochem. Soc. 1473219

Tarascon J M and Armand M 2001 Nature 414359

Vijayakumar G, Karthick S N, Sathiya Priya A R, Ramalingam S and Subramania A 2008 J. Solid State Elctrochem. 12 1135

Wang H, Huang H and Stephanie L W 2000 J. Electrochem. Soc. 1472853

Watanabe M, Sanui K, Ogata N, Kobayashi T and Ohtaki Z 1985 J. Appl. Phys. 57123

Wienk I M, Boom R M, Beerlage M A M, Bulte A M W, Smolders C A and Strathmann H 1996 J. Membrane Sci. 113 361

Wu C G, Lu M I, Tsai C C and Chuang H J 2006 J. Power Sources 159295

Xi J, Qui X, Li J, Tang X, Zhu W and Chen L 2006a J. Power Sources 157501

Xi J, Qiu X and Chen L 2006b Solid State Ion 177709

Yang G, Hou W, Sun Z and Yan Q 2005 J. Mater. Chem. 15 1369

Zhang S S, Xu K, Foster D L, Ervin M H and Jow T R 2004 J. Power Sources 125114

Zhou J and Fedkiw P S 2004 Solid State Ion 166275 